\title{
Rebirth of Comparative Literature in China from the Perspective of Medio-translatology
}

Wei Guo

Sichuan University

Follow this and additional works at: https://docs.lib.purdue.edu/clcweb

Part of the Translation Studies Commons

Dedicated to the dissemination of scholarly and professional information, Purdue University Press selects, develops, and distributes quality resources in several key subject areas for which its parent university is famous, including business, technology, health, veterinary medicine, and other selected disciplines in the humanities and sciences.

CLCWeb: Comparative Literature and Culture, the peer-reviewed, full-text, and open-access learned journal in the humanities and social sciences, publishes new scholarship following tenets of the discipline of comparative literature and the field of cultural studies designated as "comparative cultural studies." Publications in the journal are indexed in the Annual Bibliography of English Language and Literature (Chadwyck-Healey), the Arts and Humanities Citation Index (Thomson Reuters ISI), the Humanities Index (Wilson), Humanities International Complete (EBSCO), the International Bibliography of the Modern Language Association of America, and Scopus (Elsevier). The journal is affiliated with the Purdue University Press monograph series of Books in Comparative Cultural Studies. Contact: <clcweb@purdue.edu>

\section{Recommended Citation}

Guo, Wei. "Rebirth of Comparative Literature in China from the Perspective of Medio-translatology." CLCWeb: Comparative Literature and Culture 19.5 (2017): <https://doi.org/10.7771/1481-4374.3105>

This text has been double-blind peer reviewed by $2+1$ experts in the field.

The above text, published by Purdue University Press @Purdue University, has been downloaded 177 times as of $11 /$ $07 / 19$.

This document has been made available through Purdue e-Pubs, a service of the Purdue University Libraries. Please contact epubs@purdue.edu for additional information.

This is an Open Access journal. This means that it uses a funding model that does not charge readers or their institutions for access. Readers may freely read, download, copy, distribute, print, search, or link to the full texts of articles. This journal is covered under the CC BY-NC-ND license. 


\section{PURDUE}

UNIVERSITY PRESS < http://www.thepress. purdue.edu>

\section{CLCWeb: Comparative Literature and Culture}

ISSN 1481-4374 <http://docs.lib.purdue.edu/clcweb> Purdue University Press @Purdue University

CLCWeb: Comparative Literature and Culture, the peer-reviewed, full-text, and open-access learned journal in the humanities and social sciences, publishes new scholarship following tenets of the discipline of comparative literature and the field of cultural studies designated as "comparative cultural studies." In addition to the publication of articles, the journal publishes review articles of scholarly books and publishes research material in its Library Series. Publications in the journal are indexed in the Annual Bibliography of English Language and Literature (Chadwyck-Healey), the Arts and Humanities Citation Index (Thomson Reuters ISI), the Humanities Index (Wilson), Humanities International Complete (EBSCO), the International Bibliography of the Modern Language Association of America, and Scopus (Elsevier). The journal is affiliated with the Purdue University Press monograph series of Books in Comparative Cultural Studies. Contact: <clcweb@purdue.edu>

Volume 19 Issue 5 (December 2017) Article 6
Wei Guo
"Rebirth of Comparative Literature in China from the Perspective
of Medio-translatology"
<http://docs.lib.purdue.edu/clcweb/vol19/iss5/6>
Contents of CLCWeb: Comparative Literature and Culture 19.5 (2017)
Special Issue Against the "Death" of the Discipline of Comparative Literature
Ed. Shunqing Cao
<http://docs.lib.purdue.edu/clcweb/vol19/iss5/>

Abstract: In his article "Rebirth of Comparative Literature in China from the Perspective of Mediotranslatology," Wei Guo discusses the "rebirth" of Comparative Literature in China from the development of medio-translatology. He argues that, though translation has received wide attention in Comparative Literature, both domestic and foreign, especially in today's globalized world, the proposition of medio-translatology and systematic investigation by Xie Tianzhen and other Chinese scholars constitute an important way forward for translation in Comparative Literature. It makes translation an independent branch in this discipline, which is conducive to ending the longstanding confusions in translation under medio-translatology and translation studies on the whole and addressing certain controversial phenomena in translation as in the case of "creative treason" and the position of "translated literature." 


\section{Wei GUO}

\section{Rebirth of Comparative Literature in China from the Perspective of Medio-translatology}

The role of translation in Comparative Literature did not receive the attention it deserves in early period of this discipline despite its undoubted importance given to cultural communication and influence since the very beginning. Hutcheson Posnett's pioneering work, Comparative Literature, did not offer any comment on translation though he did devote chapters to the discussion of Chinese, Japanese, and Indian literatures. Another important book, Comparative Literature: The Early Years with articles contributed by renowned comparatists such as Hugo Von Merzl, Max Koch and Joseph Texte etc. covers the time span from the proposition of world literature by Johann W. von Goethe in 1827 to the attack on the validity of Comparative Literature by Benedetto Croce in 1903, with wide discussion such as the function, nature, task of Comparative Literature, but again to the unfortunate neglect of translation. Such situation only came to be gradually changed since the mid twentieth century by Paul van Tieghem.

In the book La Littérature comparée in 1931, the French comparatist Paul van Tieghem addressed the concrete issues of translation and the translator in Comparative Literature in the chapter "Medium," including the necessity, importance, accuracy, and completeness of translation and mistranslation. "Generally speaking, most readers do not have the capability to read the original text" (193). And he summarized the research on translation into two main kinds: the comparison between the source text and the translated version, and comparison among different translations of the same text, the latter of which aims to reveal "the aesthetic changes and the influences of the same writer in different times" (198). He also emphasized the role of literary life, biography, and preface of a translator in indicating translation strategies adopted by the translator in translation. Thus, the role of translation, for the first time in Comparative Literature, was brought to the fore as an important medium together with other media of individual, social environment, newspapers, and articles. This perspective on translation in Comparative Literature continued into later periods as demonstrated by Marius-Francois Guyard who in his book two decades later confirmed the value and contribution of translation and translator in promoting people's understanding of foreign literature and culture. He deemed translation as "concrete, indispensable and basic work" (Littérature 26) in Comparative Literature.

The 1980s witnessed more in-depth discussions of translation in Comparative Literature in Europe and the United States. The book What is Comparative Literature co-authored by Pierre Brunel, Claude Pichois and André-Michel Rousseau in 1983 expounds on translation from a much wider perspective where translation does not only happen in bilingual conversion, but also could be "the translation of life" (216), demonstrating the author's acute consciousness of creativity in translation. Translation is even compared to a "lab or school of invention" (217). It is worth noticing that Pierre Brunel did not seem concerned with the accuracy in translation. Rather, he elaborated on the adaptation in translation by drawing on the staged examples of novels and on the phenomenon "beautiful disloyalty" in translation, observing that "the value of a translated text does not totally lie in its accuracy compared with the source text by people (especially when the source text was written in ancient or oriental languages which allows no such comparison for us)...Thus, I would rather choose to dig deeper the strange phenomena in translation such as the disloyalty" (218). In the same vein, issues such as who the translator is, what is translated, and for what purpose, were brought to the center of translation in Comparative Literature.

The high importance attached to translation in Comparative Literature was not limited to the sphere of France at this time. Scholars in Comparative Literature from other European countries and the United States also participated in this trend, as demonstrated by perspectives on translation from Italian comparatist Franco Meregalli, Germany comparatist Horst Rudiger, Romanian comparatist Alexandru Dima and American comparatist Ulrich Weisstein, etc. For instance, Franco Meregalli regards translation as "the most important and distinguished medium in literary communication...It bridges people in different islands with natural languages and should be given the priority in research in Comparative Literature" ("On Literary" 409).

One decade later in 1990s ushered in a new age for translation in Comparative Literature. Susan Bassnett in her book Comparative Literature: A critical Introduction proposed the inclusion of Comparative Literature under Translation Studies (160-61), thus causing a wide stir on the doomed future of this discipline, which may at first glance seem "biased," but at the same time, informs us of the cultural turn in translation studies and translation turn in cultural studies. The exaggeratedness in 
such over worry on the disciplined status of Comparative Literature obviously could not hold water judging from the still presence and even prosperity of Comparative Literature around the world, especially in developing countries. And translation in Comparative Literature today inspires more interest in the literary variation in translation as demonstrated in Haun Saussy's remarks that "nothing of the work may survive of the process but the subject matter" (quoted in Ungar, "Writing" 127) and that of Steven Ungar when he agrees with Sherry Simon and advocates for making translation "integral" (quoted in Ungar, "Writing" 131) to Comparative Literature. That is, "instead of asking the traditional question which has preoccupied translation theorists-'How should we translate, what is a correct translation?' - the emphasis is placed on a descriptive approach: what do translations do, how do they circulate in the world and elicit response?" (Simon, Gender 7).

Such is a brief historical review concerning discussion of translation in Comparative Literature in Europe and the United States. Despite the fruitful efforts by scholars in this respect starting from Paul van Tieghem down to the present time, some drawbacks remain apparent and merit attention. The first aspect lies in the Euro-centrism in the discussion on translation, which is especially pronounced in the early period of Comparative Literature. Paul van Tieghem in his book classifies languages into three kinds: the first one is French; the second one includes English, German, Italian and Spanish and the last one refers to minor ones such as Hungarian, etc., all falling into the confine of European countries. Such trend continued down into the 1980 s as in Pierre Brunel's selection of translation examples, for instance, Vaugelas' translation of Quinte-Curce's works. He regards English as the link between English and Germany, and German between French and other languages of Eastern and Middle Europe (Brunel, What 63). And Ulrich Weisstein pushes this tendency an extreme with his opposition to expanding Comparative Literature to include the eastern literatures. Even in contemporary Comparative Literature, research on eastern and western comparison and translation still remains rather peripheral if seen from the whole picture of Comparative Literature as testified by the most recent ten-year report Comparative Literature in the Age of Globalization despite the pathbreaking efforts such as Gayatri Chakravorty Spivak's advocate for "planetarity" in Comparative Literature (Spivak 71).

And such an attachment to Euro-centrism could lead to the underrepresented "status" of translation in Comparative Literature as demonstrated by regarding translation as "tool" (Paul van Tieghem \& Pierre Brunel), "basics" (Guyard) and "medium" (Franco Meregalli), etc. "Translation is an indispensable tool in communication" (Van Tieghem 194). Therefore, the section concentrated on discussion of translation in Comparative Literature has usually been included under chapters titled "Medium" or "Tool: Translation and Adaptation" (Brunel 58). Thus, translation is seen more as a medium rather than an independent part in Comparative Literature, partly attributable to the fact of literary comparison within the domain of Indo-European languages where the cultural and linguistic differences may not be as large as that such as between Chinese and Germany. It may be fine if Comparative Literature is confined to European countries and the United States but obviously becomes problematic in face of the ever-increasing globalization when eastern and western literary comparison becomes an incontestable fact.

But not all stays blind to the entwined relation between translation and Comparative Literature displayed by the efforts to elevate the status of translation as in Susan Bassnett's provocative remarks, which actually constitutes the third sort of vulnerability of Comparative Literature. The proposal to include Comparative Literature under the translation studies umbrella is a sort of overrectification of the status of translation. Bassnett seems to elide distinctions between translation studies as a whole and the research focus of translation in Comparative Literature, the latter of which centers on literary translation and translated literature from the cultural perspective, being only part of translation studies. Thus, the positioning of translation in Comparative Literature by scholars from Europe and the United States on the whole tend to put translation on either end due to Euro-centrism or confusion between translation studies and translation research specifically in Comparative Literature. Chinese scholars may provide some inspiration in this aspect from their own perspective of cultural heterogeneity and understanding of the role and position of translation in Comparative Literature.

Though the disciplined status of Comparative Literature in China does not have a long history as compared with that in Europe and the United States, translation in Comparative Literature has, from the very beginning, caught the attention of the academic community here. The first book on Comparative Literature by Lu Kanghua and Sun Jingyao in the 1984 Introduction to Comparative Literature discusses translation under the section of "medium" in Chapter Two "Influence Studies" and classifies medium into three kinds: individual medium, environment medium and script medium. 
Besides, it also expounds on the issue of accuracy and completeness of translation. The breakthrough in this book lies in its proposition of the name "medio-translatology" though translation is still under the medium part and also in the definition of this term: "Medio-translatology in Comparative Literature refers to the research on translated text, translation theory and translation history" (Sun and Lu, 185 unless indicated otherwise, all translations are by Wei Guo). On the whole, the two authors do not explore too much on the translation theory and translation history but focus on the translation of certain works and the contribution of the translators in cultural communication.

Another important title in the same period is Yue Daiyun's Course Book on Eastern and Western Comparative Literature. Yue debuts the term "medio-translatology" as a section title in the discussion of translation in Comparative Literature and comes up with the definition for the term at the beginning of this section: "an important branch of influence studies in Comparative Literature-mediotranslatology refers to the comparative study of the medium role of translation and the theory and history of translation" (Yue 163), which is succeeded by a brief introduction of the history, nature, rule and theory of translation. And the issue of "creative treason," a central theory in medio-translatology later, made its debut in this book but with rather basic elaboration.

Though these two representative books in the early period of Comparative Literature in China draw widely on the theory and thought of the western counterpart, especially that of Paul van Tieghem as in the classification of different media and the inclusion of translation under the section of medium studies, translation in the two books makes a more independent presence in the name of mediotranslatology. The status of translation in Comparative Literature is largely elevated by such comments as "an important branch of influence studies," indicating the equivalent status of translation and medium studies. What's more, the two books cite widely in respect of translation examples, both domestic and foreign, thus breaking down the barrier of Euro-centrism in western research. But the advantages could not cover the weaknesses: that is, the lack of in-depth discussion in discussion of translated texts and the confusion still between translation studies, medium studies, mediotranslatology and influence studies, etc. which came to be greatly substantiated in the milestone book Medio-translatology by Xie Tianzhen in 1999.

The publication of Medio-translatology in 1999 signaled a significant step forward of research on translation in Comparative Literature by "emancipating" it from medium studies under influence studies, naming it medio-translatology. "The inadequacy of analysis and theory building of translation in literary studies becomes rather obvious in consideration of the role of translation" (Ungar, "Writing" 127), so it is the same case with the study on translation in Comparative Literature, which has been greatly improved since the development of medio-translatology. The book discusses the essential issues of medio-translatology in Comparative Literature including the definition, scope and research content of the term and addresses topics of "creative treason," translated literature and the reality and name of translated literature, etc., causing wide stir in the domestic academic community. "Starting from the perspective of medium studies in Comparative Literature at the very beginning, medio-translatology now focuses only on research of translation (especially literary translation) and translated literature from the perspective of comparative cultural studies" (Xie, "Preface" 1). Thus, research on translation under medio-translatology does not center on the linguistic conversion among different languages but rather on the distortion, addition or omission of the source text displayed in the translated version. "The value and significance of translation (mainly referring to literary translation) in the history of cultural communication stays at the core in medio-translatology" (ibid), being much narrower than translation studies in Europe and the United States. Issues such as loyalty or equivalence do not matter much here as in translation studies, as much as the excavation of cultural connotations behind "disloyalty" in translation and the role of such "disloyalty" in cultural communication.

The establishment of medio-translatology, though causing much controversy especially on its certain key terms at its first presence in the domestic circle, begins to demonstrate its advantages in research on translation within the sphere of Comparative Literature. Firstly, it helps to clarify the longstanding confusion between translation studies on the whole and the translation research in Comparative Literature. Such confusion is rather prominent both in the domestic and foreign academia before the proposition of medio-translatology. Susan Bassnett's advocate for the inclusion of Comparative Literature under translation studies; Lu Kanghua and Sun Jingyao's regard of translation theory as an important part of medium studies; Yue Daiyun's elaboration of various translation theories, such as "faithfulness, expressiveness and elegance" and of "the aim in medio-translatology lying in guidance of the translation practice" (Yue, A Course 170), etc., all of which came to be rectified with the development of medio-translatology when the scholarship in China gradually took on 
the orientation of translation under the broad sense of translation studies in Comparative Literature. Xie Tianzhen in his book classifies the differences between the two into "research perspective, focus and aim" ("Preface" 11) by reference to the Chinese translation of the term "Milky Way" by Zhao Jingshen.

The reason behind the increasingly clear view of the boundary of medio-translatology by the academic community of Comparative Literature in China is attributable to its recognition of the uniqueness of translation in this discipline (Cao, Translation Studies 1) where translation only covers the scope of literary translation.

Medio-translatology is no longer obsessed with the translation skills and methods and the linguistic accuracy among different versions. It airs no value judgment on a translation and does not orient towards the establishment of translation methods and norms but rather turns its focus to the role of translation in literary and cultural interaction so as to identify the cultural connotations of misreading and mistranslation. It centers more on the 'product' of translation, aiming to explore the underlying issues in literary communication, dissemination, influence and reception"(Cao 194). And even scholars in translation studies begin to sense and elaborate on the importance in such differentiation. For instance, Cao Minglun confirms the significance of the introduction of sociology, psychology and cultural studies (the so-called new bridges), etc. into translation studies but at the same time reminds people of the necessity in keeping the boundary of translation studies. "These new bridges are necessary but we should also be aware that the absorption of the academic fruits in translation studies should not be at the sacrifice of translation studies, causing it to lose the discipline status and become something else such as equaling it as cultural studies.... research on the linguistic dimension and its subsequent inspiration for translation methods should be the center of translation studies supplemented with other angles. (Cao 5)

Thus, the proposition and development of medio-translatology play a material role in ending the confusion of translation studies and translation in Comparative Literature by delimiting the research scope and object of translation in these two different disciplines in China. It takes translation away from medium studies so as underscore translation in intercultural communication in Comparative Literature, especially in the context of heterogeneous civilizations where the role of translation obviously surpasses the medium dimension and has a great say in literary reception and influence.

In addition, its detailed and in-depth discussion of key terms and certain phenomena in cultural communication offers illumination on the settlement of controversy over certain translation phenomena and better understandings thereof, which becomes increasingly complex and perplexed if seen only from the perspective of the traditional studies of translation. Take "creative treason" in translation for example. The notion of the term "creative treason", first coined and translated from French, could be traced back to the early comparatists. Paul van Tieghem refers to the omission and addition of content in translation in discussion of the French version of Gabriele D' Annunzio's works and emphasizes the role of the changes in different translated versions in reflection of the tastes in respective periods. Yue Daiyun in her book also relates to "creative treason" in translation. "Concretely speaking, the 'recreative' feature of translation indicates the necessity of domesticating the source text for catering to the reading taste, habit and tradition in the target context, the process of which would undergo two stages of 'treason' (one by translator and the other by the reader). And such recreation of treason is disproportional to the frequency of literary interaction and influence among the nations" (Yue, A Course 170). It is clear that this comment already includes the dimension of reader and environment in "creative treason," which would later be systematically developed by Xie Tianzhen in his book.

In Chapter Three "creative treason" in Literary Translation," Xie divides his discussion in this respect in three sections: the creativity and treason in literary translation, "creative treason" on part of the translator, and "creative treason" by reader and social environment, together with the definition and elaboration on each kind of "creative treason." It was Robert Escarpit who first proposed the concept of "creative treason" by saying that "translation is always "creative treason," which is due to the fact that "the original work is put into an unexpected reference system (mainly referring to language); and that translation is also creative means that the original work is given a new outlook and comes into contact with new readers; translation gives the original work a second life" (Escarpit, Literary 137). But Robert Escarpit's elaboration of this term seems a little bit simplified for he only identifies the change of linguistic forms in translation. The prevalence of "creative treason" in literary translation is by no means groundless but closed related with difficulty of literary translation which not only aims at the transmission of information in the source text but also at providing the target readers with the same aesthetic experience as the source texts do for the source readers. 
"Literary translation should represent the artistic context in the target text so that readers may be inspired or moved as the readers of the source text" (Mao, "Fight" 10). And often it is the recreation aspect of literary translation such as the display of the image, style, rhyme, etc. that make the matter difficult and complex. For instance, the translation of the word "rose" could be rendered into 玫瑰, 蓄薇 or 月季, etc. under different contexts due to the different cultural connotations of each rendition. The first reaction for translation of "rose" in most Chinese readers' mind would be 玫瑰 whose cultural connotations equal strong love or happiness while the other two do not have such indications. Rather, they stick more to the literal meaning of rose and could indicate a sense of detachment or gracefulness. Thus, when we translate "rose" in the sentence "When I am dead, My dearest, / Sing no sad songs for me;/Plant thou no roses at my head, /nor shady cypress tree" (Cheng "A Study on Cultural" 144) in the poem "Song: My Dearest" where the author Christina Rossitti expresses deep sorrow in separation from her lover due to religious reasons, 玫瑰 obviously is not the best solution since its connotations run counter to the sad feelings in this poem. And Xu Zhimo's rendition of the word into 蔷薇 seems more fit with the atmosphere of the whole poem. In this regard, "the creativity of literary translation is the efforts made by the interpreters to approach or reproduce the original" (Xie, On Medio-translatology 106), or more specifically, to reproduce the flavor of the source poem.

This could be a very good example of the translator's "creative treason" in literary translation, which could be further categorized into individualized translation, mistranslation and leave-out translation, compilation and abridgement, indirect translation and adaptation, etc. by Xie (111-23), some of which may seem unacceptable at first sight since it changes the form or even content of the source text if judging from the criteria of traditional study of translation. And that is why "creative treason" receives wide criticism and different appraisable in terms of its nature at its first presence. Some term it as "an indispensable strategy after thorough thoughts of the translator" (Huang, "Treason" 91) and others regard it a unique phenomenon. And we would remind readers here that "creative treason" is not the strategy in guidance of translation practice. Rather, it should be just treated as a literary phenomenon. The focus thereof should be the investigation of the underlying reasons behind such "creativeness" and "treason" and also its role in promoting cultural communication and understanding. That's where the significance of the "creative treason" lies and also the final aim of medio-translatology. For instance, Lin Shu's translation of foreign literary works includes lots of the translator's adaptation of the source work. And he even earned himself a name of king of translation without background of foreign languages and knowledge, but his role in facilitating the French cultural influence on China during that period is indisputable. And different renditions of the same poem are also indicative of poetics in different times. For instance, among the various translations of Byron's poem "The Isles of Greece," Su Manshu chooses the form of classical five-word poem and the diction such as "和亲" and "陵夷" in translation of "Where grew the arts of war and peace;/ where Delos rose and Phoebus sprung" totally domesticates the source text. But Yang Deyu later renders the poem into a more vernacular one and retains the image such as Delos and Phoebus. Wang and Peng observe, "the comparison of different versions of the same text not only reflects the style and background of the translators, but also is indicative of translation history. The turn from the use of classical form to modern free form, from domestication to foreignization tells something about the trend in translation of foreign works and also the aesthetic changes in that period" (Wang and Peng, "Comparison" 84).

And sometimes "creative treason" in translation makes the target text better known than the source one such as Wang Zuoliang's translation of the work Of Studies by Francis Bacon. Guo remarks on this possibility that "translation is creative work and good translation even exceeds the source text. It is by no means a mediocre work and sometime is more difficult than writing itself" ("On the Work" 22). No wonder that we have the metaphor "shackled dance" for translation. And "creative treason" is the personal endeavor made by the translator so as to break such "shackles" in this dilemma when the linguistic and cultural difference varies to such a large extent, be such attempt successful or unsuccessful, thorough or halfway. It already exceeds the value judgment of the "equivalence" standard in translation.

And along with priority placed upon "creative treason" in translation comes the discussion on the status of translated literature in a nation's literary history and the relevant topics. Some regard translated literature as foreign literature, which becomes increasingly criticized due to the recognition of the importance of translated work. "But such perception still exists in certain colleges where the course of translated literature is called foreign literature" (Liu, "Research" 98). The second view deems translated literature as part of national literature as elaborated in Xie's book in the chapters "Translated Literature-literature needs to be recognized" and "The Name and Reality of the History of 
Translated Literature." And the last view negates the above mentioned two standpoints and holds that translated literature should be an independent part in national literature, the three resembling the three legs of a tripod. Such a standpoint is aligned like a "scalene triangle" (Zhang, "On the position" 60) as a description of the relations among translated literature, foreign literature and national literature. "The distance between each pair of points in the triangle indicates the relation between the two kinds of literatures. The longest distance is between the foreign literature and national literature and the shortest, between foreign literature and translated literature. Thus, it is unreasonable to classify translated literature under national literature since its distance from the national literature exceeds that between translated literature and foreign literature" (Zhang 60). And a more recently developed view is that translated literature should be seen as a dynamic process, a link in the sinicization of foreign literature rather than a fixed and stable part in a country's literature. My aim here is not to judge the validity of each view but rather demonstrate the consequence it may have if we turn to the research of translation under medio-translatology, which could shed light on some overlooked yet crucial issues in the previous research. And it could become especially evident against the context of heterogeneous civilizations.

The narrowed focus on literary translation of medio-translatology in Comparative Literature on the one hand makes translation an independent branch in Comparative Literature, rather than a medium under influence studies as was the case earlier. And on the other hand, the narrowed focus also differentiates between translation in Comparative Literature and the traditional study of translation under the discipline of translation studies, the former of which "starts from the perspective of comparative culture and the latter centers on the linguistic conversion in translation" (Wang, "Translation" 1). Such differentiation becomes increasingly significant when translation occupies an essential part in literary transmission and reception, particularly among heterogeneous civilizations due to the overwhelming linguistic and cultural differences therein. For instance, "the Chinese grammar is relatively free without the constraint of tense, passive and active voice, etc...there is little emphasis on the connectives; thus, every element in a sentence, such as subject, verb and object, etc., can be omitted or reversed" (Ye, Wang 115). Thus, "equivalence" in translation, at most times, is only an ideal criterion, inaccessible to the translator.

What's more, medio-translatology in Comparative Literature could better answer the contested relations between the source text and the translation under the influence of the development in western literary theory. For instance, in traditional translation studies, the author and the source text enjoy the undisputable priority over translator and the translated version. Thus, we have all those translation criteria such as equivalence and fidelity under which circumstances, the translator should follow the source text. But now, drastically different views are proposed along with the development of feminism, deconstruction and so on, such as that translated text has the same status as the source text. Such definition stands opposed to the traditional view on translation and topics in this regard may not find good solutions in the traditional study of translation. But they could be well addressed by medio-translatology in Comparative Literature. Those different views on translation as from the traditional perspective actually aim more at displaying the uniqueness of translation from the perspective of cultural communication. They are not targeted in offering solutions for accurate translation but rather more in the role of the distortion or variation in literary dissemination.

The process of translation itself, like the real events, could never be recovered. What we have now is the "material," the translated version of the source text. Thus, I choose "translation and after translation" for the title of this paper. In Comparative Literature, "after translation" matters more than the accuracy or completeness of the translation, which constitutes the focus of research in mediotranslatology. And the sound development of medio-translatology in Comparative Literature in China is a fitting and timely response to the civilizational heterogenization of Comparative Literature, a possible and feasible way out for the discipline's predicament in the west as mainly in Europe and the United States in current times. It offers theoretical support to the development of Comparative Literature in China while at the same time also confirming and testifying the validity and objectivity of the discipline's prosperity here, for the present, and into the foreseeable future.

\section{Works Cited}

Bassnett, Susan. Comparative Literature: A critical Introduction. New Jersey: Blackwell Publishers, 1993.

Brunel, Pierre, Claude Pichois and André-Michel Rousseau. 什么是比较文学? (What is Comparative Literature). Trans. Lei Ge (葛雷). Beijing: Peking UP, 1989.

Cao, Minglun(曹明伦). "Translation Studies 在中国的名与实一一萧谈翻译学的学科范围和界线问题" ("The Chinese Names and Natures of Translation Studies"). Shanghai Journal of Translators 3(2006): 1-6. 
Cao, Shunqing (曹顺庆). 比较文学论 (On Comparative Literature). Chengdu: Sichuan UP, 2005.

Cheng, Ying (成溁). "从译介学角度看文学翻译中的几种文化意象" ("A Study on Cultural Images in Translation from Medio-translatology"). Journal of Lanzhou University 2 (2006): 143-47.

Escarpit, Robert. 文学社会学 (Literary Sociology). Trans. Meihua Wang (王美华) \& Pei Ding (丁沛). Hefei: Anhui Literature and Art Publishing House, 1987.

Guo, Moruo (郭沫若). 论文学翻译工作 (On the Work of Literary Translation). 翻译研究论文集 (1949-1983) (Anthology of Papers on Translation). Ed. Chinese Translators Association. Beijing: Foreign Language Teaching and Research P, 1984.

Guyard, Marius-Francois. 比较文学 (Littérature comparée). Trans. Bao Yan (颜保). Beijing: Peking UP, 1983.

Huang, Mingzhuang (黄明妆). "顶'仮逆'之名, 做'翻译'之实" (Treason, the Name, and Translating, the Nature一 Analyzing Creative Treason in Translation). Journal of Jimei University (philosophy and social sciences) 2(2013): 88-92.

Liu Yunhua (刘耘华). 主化视域中的翻译文学研究 (Research on Literary Translation from the Perspective of Cultural Studies). 文化与翻译 (Culture and Translation). Ed. Jianzhong Guo (郭建中). Beijing: China Translation \& Publishing Corporation, 2000.

Lu, Kanghua (卢康华) \& Sun, Jingyao (孙景尧). 比较文学导论 (An Introduction to Comparative Literature). Harbin: Heilongjiang People's Publishing House, 1984.

Meregalli, Franco. "论文学接受" ("On Literary Reception"). 比较文学研究译文集 (Anthology of Papers on Comparative Literature). Ed. Yongchang Gan (干永昌). Shanghai: Shanghai Translation Publishing House, 1985.

Mao, Dun (茅盾). "为发展文学翻译事业和提高翻译质量而奋斗" ("Fight for the Cause of Literary Translation and the Improvement of Translation Quality"). 翻译研究论文集 (1949-1983) (Anthology of Papers on Translation). Ed. Chinese Translators Association. Beijing: Foreign Language Teaching and Research Press, 1984.

Simon, Sherry. Gender in Translation: Cultural Identity and the Politics of Transmission. New York: Routledge, 1996.

Spivak, Gayatri. C. Death of a Discilpine. New York: Columbia UP, 2003.

Su, Manshu (苏曼殊). 苏曼殊集 (A Collection of Su Manshu's works). Beijing: People's Publishing House, 2008.

Ungar, Steven. "Writing in Tongues: Thoughts on the Work of Translation". Comparative Literature in an Age of Globalization. Ed. Saussy, Haun. Baltimore: The Johns Hopkins UP, 2006. 127-38.

Van Tieghem, Paul(梵·第根). 比较文学论 (La Littérature comparée). Trans. Wangshu Dai(戴望舒翻). Beijing: The Commercial P, 1937.

Wang, Xueqin (王雪琴) \& Peng, Jingfei (彭静飞). "拜伦《袁希腊》四篇译文的比较分析" ("Comparison of the Four Translated Versions of The Isles of Greece by Byron"). Journal of Changchun University of Science and Technology (Social Sciences Edition) 9(2011): 83-85.

Wang, Xiangyuan (王向远). "翻译学·译介学·译文学一三种研究模式与'译文学'研究的立场方法" ("Translation Studies, Mediotranslatology and Translation of Literary Works-Three kinds of Research Modes and the Research Position of "Translation of Literary Works"). Journal of Anhui University (social sciences) 4(2014):1-8.

Xie, Tianzhen (谢天振). 译介学 (On Medio-translatology). Nanjing: Yilin Press, 2013.

Yang Deyu (杨德豫). 看伦抒情诗选 (A Selective Anthology of Byron's Poems). Changsha: Hunan Literature and Art Publishing House, 1996.

Ye, Jiaying (叶嘉芗). 王国维及其女学评论 (Wang Guowei and His Literary Criticism). Hebei: Hebei Education P, 1997.

Yue, Daiyun (乐黛云). 中西比较文学教程 (A Course Book on Eastern and Western Comparative Literature). Beijing: Higher Education P, 1988.

Zhang, Youyi (张友谊). "翻译文学归属之研究—'不等边三角形'论" ("On the Position of Translated Literature一from the view of 'scalene triangle'"). Journal of Huazhong Normal University (Humanities and Social Sciences) 5(2006): 58-60.

Author's profile: Wei Guo (国威) teaches literature, culture, and Buddhism at the Sichuan University College of Literature and Journalism. His interests in scholarship include cultural studies, media studies, comparative poetics, and classical Chinese literature and Buddhism. Guo's publications include: "作为宗派的存在一中国律宗研究综述" ("An Overview of Chinese Lvzong Research"), The Religious Cultures in the World (2014)，"跨时空对话：德里达解构主义与僧 肇中观思想-一以异质性为中心 "("Cross spatio-temporal Dialogue: Derrida's Deconstructuralism and Madhyamapratipad Thoughts-with a Focus on Heterogeneity"), Cultural Studies and Literary Theory (2014). and " 闽中名刹 梅峰古寺一记福建莆田梅峰光孝寺" ("On the Fujian Putian Miefeng Guangxiao Temple"), China Religion (2013). E-mail: <guowei@ scu.edu.cn> 